\title{
The Doctor-Public Relationship: How Physicians Can Communicate to Foster Resilience and Promote Mental Health During COVID-19
}

\author{
Mary C. Vance, MD, MSc ${ }^{1,2}$ [1] and Joshua C. Morganstein, $M D^{7}$ \\ ${ }^{1}$ Center for the Study of Traumatic Stress, Department of Psychiatry, Uniformed Services University, Bethesda, MD, USA; ${ }^{2}$ Henry M. Jackson \\ Foundation for the Advancement of Military Medicine, Bethesda, MD, USA.
}

$\mathrm{J}$ Gen Intern Med 35(12):3697-8

DOI: $10.1007 / \mathrm{s} 11606-020-06243-\mathrm{w}$

(c) Society of General Internal Medicine (This is a U.S. government work and not under copyright protection in the U.S.; foreign copyright protection may apply) 2020

A s physicians, we are traditionally taught to diagnose and treat one patient at a time. The doctor-patient relationship, that empathic alliance at the heart of medicine, reflects our abiding commitment to caring for individual patients who are suffering. However, during the COVID-19 pandemic, suffering is occurring on a massive scale that threatens to overwhelm the "one patient at a time" approach. Previous large-scale national disasters, potentially less impactful than COVID-19, resulted in significant mental health costs to society. ${ }^{1}$ This suggests that the mental health "footprint" of the current pandemic will be far-reaching and long-lasting, and that proactive, preventive public health measures must be taken to address the rapidly evolving, ongoing, and future mental health effects of COVID-19. ${ }^{2}$

Disaster psychiatry, which combines elements of population health and preventive medicine, offers insights into the public health measures that can be taken to mitigate the mental health effects of this pandemic and other disasters. In particular, it teaches us that communication with the public is key: effective risk and crisis communication techniques ${ }^{3}$ that promote a sense of safety, calming, self- and community-efficacy, social connectedness, and hope ${ }^{4}$ can alter the trajectory of recovery for entire communities and populations.

Physicians have a critical role to play in communicating with the public during the current crisis. We are de facto public health leaders: our patients, institutions, and communities look to us for expert guidance on the health consequences, including mental health impacts, resulting from COVID-19 and steps to effectively address those. We may have the opportunity to provide resources or comments to media outlets,

Received August 25, 2020

Accepted September 11, 2020

Published online September 18, 2020 hospital/clinic committees, community organizations (e.g., schools, places of worship), and other venues. As such, we are ideally positioned to support public health by establishing, in addition to a doctor-patient relationship between ourselves and our patients, a "doctor-public relationship" between ourselves and the communities looking to us for guidance.

Yet the role of public health leader and crisis communicator during a pandemic or other disaster may be difficult for physicians to intuit, as it requires us to speak to a diversity of lay audiences in varied settings rather than to specific patients in our offices. Here, we present a few important principles and actionable steps in communication, gleaned from field experience and research literature in disaster psychiatry, that will help physicians foster an effective "doctor-public relationship" during COVID-19 and other disasters:

1. A range of psychological and behavioral responses occurs following disasters, many of which do not meet formal criteria for a psychiatric diagnosis. An overemphasis on diagnosis and treatment following COVID-19 and other disasters runs the risk of pathologizing what can better be conceived of as normal reactions to abnormal circumstances. Far more common and occurring much earlier than psychological disorders are distress reactions (e.g., insomnia, decreased feelings of safety, irritability, distractibility) and health risk behaviors (e.g., increase in alcohol use, over-dedication to work, family conflict), which can have profound implications for public health despite the lack of a clear diagnostic label. ${ }^{5}$ For instance, an increase in alcohol use, even in the absence of a diagnosis of alcohol use disorder, can result in numerous adverse consequences (e.g., motor vehicle accidents, intimate partner violence, medical errors, workplace presenteeism). Actionable steps: Educate patients and the public on common and expectable responses, facilitate the use of healthy coping mechanisms, and inform about when to seek additional assistance. Rephrase sensationalized language in a way that normalizes reactions - e.g., by framing the gathering of supplies in preparation for an emergency as "being prepared" rather than "panic-buying."

2. The behaviors that individuals choose to engage in during this pandemic are largely dependent on the 
public's perception of risk, rather than actual risk. Risk perception has influenced decisions to practice physical distancing, wear face coverings, and follow stay-at-home recommendations. It has also influenced patterns of routine and preventive healthcare utilization as well as engagement with the economy, resulting in numerous detrimental effects on physical and mental health. Physicians can help prevent and mitigate the effects of this costly imbalance between perceived risk and actual risk during our nation's reopening process by utilizing established communication principles ${ }^{4}$ with our patients and the general public that shape an accurate perception of risk. Importantly, although we as physicians are comfortable with medical language, research has shown that use of scientific jargon impairs the ability of the general public to process information and may undermine efforts at persuasion. ${ }^{6}$ Actionable steps: Provide information that is timely, accurate, and updated; avoid false reassurances; use credible messengers, such as physicians and scientists; and limit medical jargon.

3. Beyond the written and spoken word, rituals and symbols are powerful tools for creating togetherness. With so many of our pre-established social and cultural rituals being disrupted (e.g., weddings, funerals, religious services, birthday parties, baby showers), it is particularly important for people to create and incorporate new rituals and symbolic acts to feel a sense of cohesion. As studies of previous disasters have shown, ${ }^{7}$ rituals and symbols often have the power to offer healing, create connections, and bridge divides in a way that transcends written or spoken word. For some, they may also be an easier or more acceptable form of expressing emotion than the use of language. Examples of new or modified rituals created during the pandemic include drive-by celebrations or events and collective clapping for healthcare workers at a set time in cities across the USA. Actionable step: Encourage patients and the public to create rituals and symbols to celebrate together, mourn together, and help each other persevere.

Whether we know it or not, we are all receiving a "crash course" in disaster psychiatry right now, with the daily challenges to mental health and wellbeing that the COVID-19 pandemic places on ourselves, our patients, our communities, and our nation. Articulating and applying these principles through skilled communication with the public enable physicians to serve as both doctors and public health leaders, and to harness the power of the "doctor-public relationship" to speed our collective recovery in the post-pandemic world.

Corresponding Author: Mary C. Vance, MD, MSc; Center for the Study of Traumatic Stress, Department of Psychiatry, Uniformed Services University, Bethesda, MD, USA (e-mail: mary.vance. ctr@usuhs.edu).

\section{Compliance with Ethical Standards:}

Disclaimer: The opinions and assertions expressed herein are those of the authors and do not necessarily reflect the official policy or position of the Uniformed Services University, the Henry M. Jackson Foundation for the Advancement of Military Medicine, the Department of Defense, or the US government.

Conflict of Interest: Dr. Vance and Dr. Morganstein have no conflicts of interest.

\section{REFERENCES}

1. Schoenbaum M, Butler B, Kataoka S, Norquist G, Springgate B, Sullivan G, et al. Promoting mental health recovery after hurricanes Katrina and Rita: what can be done at what cost. Arch Gen Psychiatry. 2009; 66(8), 906-914. https://doi.org/10.1001/archgenpsychiatry.2009. 77

2. Galea S, Merchant RM, Lurie N. The Mental Health Consequences of COVID-19 and Physical Distancing: The Need for Prevention and Early Intervention. JAMA Intern Med. 2020; https://doi.org/10.1001/jamainternmed.2020.1562. Advance online publication.

3. Reynolds B, Seeger MW. Crisis and emergency risk communication as an integrative model. J Health Commun, 2005; 10(1), 43-55. https://doi.org/ 10.1080/10810730590904571

4. Hobfoll SE, Watson P, Bell CC, Bryant RA, Brymer MJ, Friedman MJ, et al. Five essential elements of immediate and mid-term mass trauma intervention: empirical evidence. Psychiatry. 2007; 70(4), 283-315 discussion 316-69. https://doi.org/10.1521/psyc.2007.70.4.283

5. Norris FH, Friedman MJ, Watson PJ, Byrne CM, Diaz E, Kaniasty K. 60,000 disaster victims speak: Part I. An empirical review of the empirical literature, 1981-2001. Psychiatry. 2002; 65(3), 207-239. https://doi.org/ 10.1521/psyc.65.3.207.20173

6. Bullock OM, Colón Amill D, Shulman HC, Dixon GN. Jargon as a barrier to effective science communication: Evidence from metacognition. Public Underst Sci (Bristol, Engl). 2019; 28(7), 845-853. https://doi.org/10. 1177/0963662519865687

7. Danbolt $\mathbf{L}$, Stifoss-Hanssen H. Public Disaster Ritual in the Local Community: A study of Norwegian cases. J Ritual Stud. 2011; 25(2), 2536. Retrieved August 24, 2020, from http://www.jstor.org/stable/ 44368878

Publisher's Note: Springer Nature remains neutral with regard to jurisdictional claims in published maps and institutional affiliations. 